\title{
Mito y feminismo en Marassá y la nada de Alanna Lockward
}

En la novela Marassá y la Nada (2013), la escritora dominicana Alanna Lockward realiza algo insólito en la tradición literaria dominicana: adentrarse en la geografía y cultura haitiana totalmente desprovista de prejuicios. El título, que evoca la figura de Marassá, los Gemelos Divinos del panteón vudú haitiano, sugiere un concepto de hermandad que, al verse reforzado por una visión feminista y decolonial, se presta para una interpretación de esta figura como una propuesta de relación entre Haití y República Dominicana que se aparta de los modelos de antagonismo y "conflicto fatal" que permean los debates sobre la dinámica entre ambas naciones. Al contrario, la figura de Marassá propone una síntesis de mitos occidentales y africanos y ofrece un modelo basado en la mutua dependencia, solidaridad y fraternidad.

En A Wedding in Haiti (20II), la escritora domínico-americana Julia Álvarez narra la experiencia de su primer viaje a Haití, viaje que emprendió para asistir a la boda de Piti, un joven trabajador haitiano a quien había empleado en su finca en República Dominicana y con quien se había encariñado hasta el punto de prometerle ser su madrina de bodas. El relato evoca la mezcla de afecto, curiosidad y aprehensión de la autora, quien se refiere a Haití como esa gran hermana desconocida, esa hermana de quien sabía tan poco. En su nota al inicio del texto, Álvarez expresa cómo su amistad con Piti y su familia le ha enseñado lo mucho que es posible cuando se cruzan las fronteras que separan ambos pueblos. Su observación es muy significativa sobre todo cuando se toma en cuenta que, en el imaginario dominicano, cruzar a Haití, tanto física como simbólicamente (o literariamente) equivale a transgredir una frontera más sicológica y política (y por tanto, más difícil y riesgosa) que geográfica. Quizás sea por ello que a pesar de la abundancia del corpus literario dominicano sobre el tema haitiano (incluyendo textos sobre la masacre de I937 y la extrema pobreza y explotación de los trabajadores haitianos en los bateyes) sean pocos los que se adentren en la geografía y cultura haitianas o que, cuando lo hacen, las representen sin prejuicios ni estereotipos. Una notable excepción es el largo poema Las metamorfosis de Makandal (1998) de Manuel Rueda, quien se enfoca en el líder 
revolucionario Makandal como figura espiritual de lucha y resistencia contra la opresión. La presencia de la figura mítica de Makandal para reescribir la historia de la isla sirve de antecedente para el tema que me ocupa aquí, que es el del empleo del mito como narrativa fundacional de una nación o, mejor aún, como su contrario: el mito como posible narrativa subversiva de fundaciones anteriores. ${ }^{\text {I }}$

Según Roland Barthes, el mito es un sistema de comunicación, un modo de significación, un mensaje. Puede ser oral pero también puede estar formado por la escritura o por representaciones. En este sentido, el discurso escrito, la fotografía, el cine, el reportaje, el deporte, los espectáculos, la publicidad -todo puede servir de soporte a la palabra mítica, la cual, como sistema semiológico que es, puede ser desglosada en signo, significante y significado (I8I-190). Más recientemente, Wendy Doniger analiza el impacto del mito en la sociedad que la crea y reproduce, y establece que, para esta sociedad, el mito no es una mentira, sino un "relato que se cree, que se cree ser verdad, y que la gente sigue creyendo a pesar de que a veces existe una enorme evidencia de que es, de hecho, una mentira" (2-3; énfasis en el original). Doniger enfatiza dos aspectos fundamentales de los mitos: el aspecto microscópico, que es el de la experiencia vivida por un personaje en particular, aspecto cuyos detalles se pueden analizar en profundidad como si estuvieran bajo un microscopio; y el aspecto telescópico, que es donde se encuentran las experiencias "inimaginablemente grandiosas", las experiencias vividas por millones. Por consiguiente, Doniger propone analizar mitos sirviéndonos tanto del microscopio para desmenuzar e interpretar cada detalle cultural o simbólico, como del telescopio para obtener "the big picture", una visión a gran escala de problemáticas que van más allá de un personaje y que incluyen a toda una población. Este aspecto telescópico le da un carácter político a los mitos, pues aunque parezcan referirse a dioses o a temas externos a la cotidianidad humana, no por ello son discursos apolíticos $(2 \mathrm{O}-2 \mathrm{I})$.

En el contexto de las relaciones domínico-haitianas, uno de los mitos principales con que se ha construido Haití en el imaginario dominicano es la figura del cuco, descendiente del comegente, imagen caníbal con que se representó a los esclavos de Saint-Domingue que osaron rebelarse contra sus amos franceses. Este ser monstruoso aparece en relatos de crímenes, leyendas, cuentos y novelas, desde las cartas que el Arzobispo Fernando Portillo escribiera en I79I, hasta la reimpresión en el siglo XX de cuentos y novelas sobre este tema (Johnson; Jáuregui; González; Ubaldo; Delgado Pantaleón). Con el tiempo, esta imagen se fue transformando en el cuco, figura abstracta con poderes sobrenaturales que devora a niños, mujeres y 
ancianos por las noches. El cuco es la figura mítica por antonomasia en el imaginario nacional, pues también le ha servido a ideólogos y políticos del siglo XX para fabricar la imagen de una nación caníbal, Haití, que devoraría a la nación dominicana con invasiones pacíficas. ${ }^{2}$

Como resistencia a este fatídico mensaje, propongo aquí explorar la figura de Marassá, una deidad del vudú haitiano compuesta de dos hermanos/hermanas gemelos/gemelas, y que, como veremos a continuación, podría resultar un mito más representativo de las relaciones entre ambos países.

Tal como ha sugerido la crítica VèVè Clark, la figura de Marassá surge como un signo que desestabiliza el sistema binario que ha caracterizado la experiencia del Caribe en su conjunto (43-44). Aquí me sirvo del argumento de Clark, así como de los trabajos antropológicos de Maya Deren y Marilyn Houlberg para localizar el signo de Marassá no sólo en el Caribe sino, más precisamente, en la isla compartida por Haití y la República Dominicana - la isla dividida que dio origen a esta figura - para confirmar que Marassá puede, de hecho, desestablizar el sistema binario, sobre todo aquel estructurado en el paradigma del cuco, o de Haití como nación cannibal. En este sentido, Marassá podría ofrecer un nuevo mito fundacional que representaría a ambas naciones, no como enemigos eternos sino como mellizos nacidos de la misma madre (isla), y que se encuentran en profunda necesidad de re-conocerse, complementarse y empoderarse mutuamente.

En la literatura dominicana, esta figura surge en el título de la novela Marassá y la Nada (2013), de Alanna Lockward, quien, además de ser escritora, fue una de las primeras periodistas dominicanas en aventurarse a Haití a mediados de los noventa y enviar reportajes sobre lo que pudo observar en la década siguiente a la caída de Duvalier. ${ }^{3}$ Ante todo, conviene señalar que la novela contiene figuras históricas y míticas precolombinas, veneradas tanto por los dominicanos como por los haitianos, como la cacica taína Anacaona, la Virgen de la Altagracia y los Marassá. A mi modo de ver, el alto calibre simbólico de estas figuras podría explotarse para reformularlas como alternativas a modelos patriarcales y colonialistas. Por un lado, si bien la figura de la Virgen de la Altagracia pertenece a la tradición católica, el hecho de que sea reverenciada por los fieles de ambos lados de la isla es un punto de acercamiento a nivel de creencias espirituales. Por otro lado, Anacaona, reina que combatió a los colonizadores, aunque al final fue vencida, también es honrada por haitianos y dominicanos y evoca la resistencia contra un opresor común. Finalmente, los Marassá surgen como símbolo de una hermandad que tiene mucho más que ganar a través de la coexistencia pacífica y 
armoniosa que a través de la hostilidad y la rivalidad con que se ha tratado de dividir a los pueblos de ambos lados de la isla.

Enmarcada por unas coordenadas geográficas que delinean un triángulo global entre París, Nueva York y la isla compartida por Haití y República Dominicana, la trama de Marassá y la Nada se inicia con la tragedia de dos hermanas: Laura, que vive en París y se suicida, y Mara, que vive en Santo Domingo, absorbe esa muerte y se deja morir de hambre. Una tercera mujer, Moira, prima de las anteriores y residente en Nueva York, narra la historia de las hermanas a la vez que se desplaza a Santo Domingo para salvar a Mara de la inanición. Moira aprovecha este viaje para cruzar a Haití en busca de los restos de la madre de las hermanas, Doña Manuela Ricart de Porter, quien se había ido allí en un retiro espiritual, desapareciendo sin dejar la menor huella. El viaje de Moira a Haití es una oportunidad para describirlo más allá de las conocidas referencias a la pobreza, lo dantesco o lo sensacional. Lejos de ello, la narradora ofrece una mirada desprovista de estereotipos, lo cual es aún más potente cuando se considera el aspecto transgresivo que significa cruzar la frontera y abrazar sin prejuicios al "otro lado".

La novela contiene dos aspectos míticos fundamentales: por un lado se sirve de figuras históricas y mítico-religiosas reverenciadas en ambos lados de la isla, y, por otro, se nutre de una visión profundamente feminista. Para empezar, se trata de un texto poblado principalmente por personajes femeninos: Laura, Mara, Moira y su madre Manuela llevan la trama, mientras que otras mujeres, como Casandra, una adivinadora dominicana que vive en Haití, ofrecen palabras premonitorias y de sabiduría. Por otro lado, Carmen, una bióloga mexicana, investiga la historia precolombina de la isla en busca de vestigios del solenodonte, una especie prehistórica emparentada al dinosaurio que vivió en la isla en otros milenios. Así surge una figura triple, o trilliza, de tejedoras del tiempo que incluye a Moira hilvanando la narración del presente, Casandra entrelazando los hilos del futuro y Carmen escarbando en un pasado mucho anterior a la colonización o a la presencia humana. Las tres son precedidas en el tiempo por una madre ancestral, la tatarabuela de Moira, Gloria Stephenson de Porter, quien aparece como referencia a un siglo anterior, cuando esclavos libertos de los Estados Unidos fueron enviados a vivir a Santo Domingo entre I 824 y I 826 , período en que esa parte de la isla se encontraba bajo el régimen haitiano y, por consiguiente, había abolido la esclavitud. ${ }^{4}$ De este modo, la presencia de Gloria sirve para inscribir en el texto, aunque de manera secundaria en la trama, la emancipación de los esclavizados que tuvo lugar bajo el régimen haitiano de I822 a I844. 
Otras importantes referencias a figuras femeninas incluyen la descripción de un retrato de Anacaona, así como múltiples referencias a la Virgen de la Altagracia, patrona de la República Dominicana, también reverenciada por los haitianos, quienes parten en peregrinaciones multitudinarias hasta el extremo este de la isla, en Higüey, donde se encuentra la Basílica de la Virgen en República Dominicana. La presencia de la Virgen de la Altagracia, que en Haití se llama Altagrace, sirve para enfatizar lazos espirituales que unen a ambos lados de la isla y que raras veces se pone de relieve en las narrativas tradicionales sobre ambos pueblos. Este lazo espiritual se ve reforzado por lazos históricos que surgen a través de Anacaona, cuya descripción, de fuerte tono feminista, subvierte normas patriarcales y colonialistas y reescribe la historia:

[E]n Pétion-Ville en un restaurante que se llama Anacaona ... Un retrato descascarado y rodeado de flores, en el fondo del patio, muestra a la cacica taína que, además, también era poeta - no semidesnuda y a los pies de Colón como en el monumento frente a la catedral de Santo Domingo, sino vestida en un dos piezas de plumas carmesí que dejan al descubierto su vientre ondulante y mestizo, muy sexy, como el de Shakira. Una lanza sobre el suelo, erecta entre sus manos, resalta el gesto desafiante de Anacaona, que es como el de la Mujer Maravilla cuando está a punto de atacar un transgresor de la ley. Una leyenda traduce el significado de su nombre arahuaco al inglés: "Golden Flower", y más abajo reza: "Haitian Leader, I490". Es decir dos años antes de que llegaran los españoles a su "nuevo mundo" a impregnar la isla de su lengua de erres ligeras y genocidas, y su evangelio de esclavitud y exterminio. Alumbrados por este credo, fueron desapareciendo Anacaona y todos los aborígenes del Caribe en más o menos dieciocho años y nació más tarde el Atlántico Negro, bautizado por un cura jerónimo que predicaba que los Negros eran unos desalmados - es decir, que no tenían alma - y que por eso no podían entrar al cielo. Los africanos llegaron para salvar a los poquísimos arahuacos que aún quedaban vivos en la barriga insaciable de la ballena... (8I-82).

Esta descripción compara el retrato de la soberana en Pétionville con la escultura de una Anacaona conquistada y colonizada que se erigió en i887 en el parque Colón, frente a la Catedral Primada de Santo Domingo, ambos monumentos coloniales por excelencia. En la misma, una escultura que se dice es Anacaona, aunque nada lo indique por escrito, aparece semidesnuda a los pies del Descubridor, subyugada por su opresor. El mismo hecho de que la dedicatoria de la escultura no indique su nombre implica su insignificancia simbólica, pues parece que para el escultor francés Ernesto Gilbert y los que comisionaron su obra daba igual que se tratara de Anacaona o de cualquier indígena. De esta manera se 
distorsionó o se borró, en estos monumentos, el aspecto de resistencia de la cacica. Muy distinta es la imagen presentada en este restaurante de Pétionville: una cacica llena de fuerza e integridad, desafiante ante el poder masculino y colonizador, y asociada a figuras que, como Shakira y la Mujer Maravilla, evocan poder femenino en el imaginario colectivo de hoy, tanto el poder de la que subyuga a los hombres con su sensualidad como el de la que captura a los malhechores con su célebre lazo, sometiéndolos a su merced. Es decir, a través de esta representación, Moira revela una Anacaona que no se dejó vencer ni humillar y que se yergue como modelo de resistencia.

Esta Anacaona, cuya imagen confiere poder y dignidad a la mujer y al sujeto precolombino contrasta con el poema Anacaona (I880) de Salomé Ureña, quien al rendirle homenaje al valor de la reina taína preservó su visión de un Colón noble y bueno y se mantuvo fiel a la hispanofilia que marcaba la sociedad dominicana del siglo diecinueve (Torres-Saillant, Intellectual 208). De hecho, la Anacaona representada por Lockward surge como una crítica al hecho de que en República Dominicana los monumentos hagan parecer que el acto genocida y esclavista español aún se celebra como si fuera digno de orgullo patrio. En este sentido, la Anacaona de Lockward se aproxima a la imagen ofrecida en Anacaona (1986), obra teatral del autor haitiano Jean Métellus que denuncia el acto barbárico de los españoles y sugiere que la destrucción del cacicazgo de Jaragua, del cual era reina Anacaona, sirvió para evitar una posible alianza entre indios y africanos. Aquí Métellus muestra una visión de resistencia anticolonialista y propone un final en el que los rebeldes se embarcarían en una lucha por la libertad. ${ }^{5}$

Si aplicamos el lente microscópico propuesto por Doniger, observamos que el aspecto feminista de la novela surge de manera más sutil y compleja en el contenido simbólico del nombre Moira, que es una variante del griego Moerae, el nombre colectivo de las Parcas, Clotho, Lachesis y Atropos. En la mitología griega, las Parcas, quienes también son hermanas siamesas, llevan el hilo de la vida. La primera es la "hiladora", la segunda la "medidora" y la tercera "la que no puede evitarse", es decir la que corta el hilo de la vida. Moira también significa "fase", como en las fases de la luna, que, según los griegos, son tres y corresponden a tres personas. Asimismo, estas tres hijas de Zeus fueron asignadas con la tarea de inventar el alfabeto, tarea ésta que vincula la escritura al hilo de la vida (Graves 48, 65). En este sentido, Moira o Moerae sugiere la idea de mutua dependencia de las tres hermanas, cuya obra no puede iniciarse ni concluirse sin el aporte de cada una. 
Al conectarse lo mítico con lo literario, la figura de Moira evoca la crítica feminista que se nutre de los enlaces teóricos entre el hilar y el escribir, entre el tejido y el texto (Kristeva; Barthes). En el ensayo "Arachnologies: The Woman, the Text, the Critic", la crítica estadounidense Nancy K. Miller examina la figura de Aracne, aquella mujer de la mitología griega que tejía tapices de manera tan diestra y hermosa que provocó los celos de la diosa Atenea, quien castigó su osadía convirtiéndola en araña. Miller añade otras leyendas, como la de Filomela, cuyo esposo, después de violarla, le cortó la lengua para que no pudiera contar su desgracia. Filomela venció este atroz obstáculo tejiendo un tapiz con imágenes que narraban visualmente la historia de su violación y se la envió a su hermana, quien pudo venir a rescatarla. Para Miller, las historias de Aracne y de Filomela se pueden interpretar como una "figuración" o encarnación de la relación de producción de la mujer con la cultura dominante, es decir, como una posible parábola (o modelo de crítica) de una poética feminista (270-295). En mi opinión, si bien la historia de Aracne evoca una imagen de rivalidad entre Aracne y la poderosa Atenea (y, por tanto, problemas de clase, no de género), la de Filomela, en cambio, brinda la noción de solidaridad entre hermanas, la acción conjunta de mujeres resistentes ante el atropello patriarcal.

Por lo general, las figuras dobles o triples de hermanos y hermanas en las tradiciones míticas suelen reproducir dos grandes modelos. El primero es el modelo antagónico, poblado por sentimientos de rivalidad, celos y odio, cuyo mejor ejemplo reside quizás en las figuras de Caín y Abel. El otro modelo es el de la solidaridad y mutua dependencia, como el caso de Filomela y su hermana. A mi modo de ver, lo interesante de Marassá y la Nada es su capacidad sincrética (o, como diría Edouard Glissant, de creolización) de tradiciones occidentales y africanas. ${ }^{6}$ La novela es capaz de aludir a figuras trillizas europeas como las Parcas y recoger al mismo tiempo figuras dobles o triples como los Marassá, deidad de la cosmogonía del vudú haitiano también conocida como los Gemelos Divinos o primeras creaciones de Dios. Esta figura, que también existe en el vudú dominicano, se presta al contexto dominico-haitiano, sobre todo cuando se toman en cuenta posiciones que, como la de Julia Álvarez, consideran a Haití como ese gran hermano de la República Dominicana. De hecho, el término de hermanos aparece con frecuencia en discursos de figuras históricas dominicanas, como Juan Pablo Duarte, José María Imbert y Gregorio Luperón (Lora I9I, 199-200), y personalidades contemporáneas como el diplomático haitiano Guy Alexandre (2013) y el escritor domínicoamericano Junot Díaz, entre otros intelectuales y artistas de ambos lados de la isla, que han expresado su mutua solidaridad y afecto. Por 
consiguiente, la imagen de Marassá surge como una rica figura simbólica para expresar un modelo de relación más representativa de la dinámica real entre ambas naciones.

Antes de examinar a fondo la figura de los Marassá, cabe recordar brevemente el trabajo de la investigadora Maya Deren, según la cual, en la cosmogonía del vudú, el mundo de lo "invisible" se concibe dentro de un espejo cósmico ("loco-miroir") a través del cual se invocan los espíritus o luases $\left(2 \mathrm{I}^{-} 4 \mathrm{O}, 222\right) .^{7}$ La metáfora de la profundidad de este espejo cósmico se manifiesta en las encrucijadas ("croisements de chemins"). Su símbolo es la cruz, pero no se trata sólo de cruces de caminos en la superficie de la tierra, que sería un plano horizontal determinado por los puntos cardinales, sino de la intersección entre el plano horizontal, que es el mundo de los mortales, y el plano vertical, que es el mundo metafísico. En esta encrucijada o intersección, ambos mundos se comunican y establecen el tráfico de energías entre ellos. Es aquí donde debe colocarse, en los rituales, el alimento de los luases y donde ellos hacen su aparición para actuar sobre el mundo material (35-36).

Una forma de correspondencia entre el mundo metafísico y el material se da cuando un luá rige la vida de un individuo en particular. En este contexto, los Marassá Divinos rigen la vida de los hermanos o hermanas gemelos/as nacidos en cualquier familia. Estos pueden ser del mismo sexo o no, idénticos o no, y pueden ser dos (marassa deux) o tres (marassa trois) si son trillizos, y así sucesivamente. El hijo y la hija nacidos después de los gemelos se llaman "dossou" o "dossa" y se pueden integrar a los Marassá en la figura triple de "marassa trois", que es como aparece en su vevé o representación visual. También existen varias categorías de gemelos: los vivos, los muertos, los ancestros y los Marassá Divinos. Según Deren, como los gemelos son, en esencia, uno, lo que perjudica a uno perjudica al otro, y cualquier accidente o enfermedad que afecte a un gemelo constituye una amenaza para el segundo. De igual manera, una separación violenta de los dos puede acarrear un desastre; por consiguiente, las familias hacen grandes esfuerzos para que los actos importantes de la vida, como un matrimonio, se realicen al mismo tiempo para los dos. En la lectura de Deren, lo que prevalece es la interdependencia, el énfasis en que los gemelos no se deben separar en un dualismo competitivo y conflictivo (3940).

En contraste con esta visión de inseparabilidad y armonía, en su estudio del vudú haitiano, el etnólogo suizo Alfred Métraux enfatiza lo que para él es un potencial de rivalidad y antagonismo que traen consigo los marassá y que sería necesario mantener apaciguado (I46-153). Para Métraux, es normal que los gemelos se odien: "Marassa yo raisab" (los 
gemelos no se llevan bien). En su lectura, los Marassá son figuras infantiles a las cuales hay que supervisar de cerca para impedir que se hagan daño el uno al otro. Reconoce, sin embargo, que su poder no es "totalmente negativo" y que siempre que se mantengan felices y satisfechos, pueden canalizar su poder hacia el bien (150-15I).

Por otra parte, en su reciente estudio sobre las figuras gemelas, Marilyn Houlberg enfatiza el gran poder de los gemelos en la tradición del vudú haitiano. Una gran característica es que les encanta comer y son capaces de hacer travesuras con tal de obtener más comida. La creencia es que requieren más alimento y más atención médica y espiritual debido a su peso inferior al nacer. En lo simbólico, se les asocia con lugares de transición como los umbrales, los bordes y lugares místicamente peligrosos como las encrucijadas. Los Marassá se unen a Papa Legba como guardianes de las encrucijadas, donde el mundo de arriba se une al mundo de abajo y el mundo de los vivos toca el de los muertos (I3-I4). En su investigación del origen africano de los Marassá, Houlberg concluye que es una creolización de varias culturas africanas. Por un lado, el término creole marasa se deriva de la palabra kikonga mabassa, que significa "aquellos que vienen divididos," o "el que viene en forma de dos", mientras que el término dosou (dosa) se deriva del fon docu, que significa el niño o la niña que nace después de mellizos. Por otro lado, Houlberg también asocia a los mellizos con la preponderancia del dualismo en la cosmogonía fon, cuyo propio panteón está encabezado por la divinidad creadora Mawu-Lisa, que es un par de mellizos. Sostiene Houlberg, citando a Paul Mercier, que en estas tradiciones africanas, el tipo ideal en el mundo divino es un par de mellizos del sexo opuesto o, de manera más rara, del mismo sexo: "Esta estructura melliza de los dioses es la regla" (15). Para Houlberg, la importancia de los mellizos en África y su diáspora se conecta al hecho de que la frecuencia de nacimientos mellizos en África es mucho más alta que en cualquier otra parte del mundo (I6). Las conclusiones de Houlberg se asemejan a las de otros especialistas que sostienen que en las culturas africanas y precolombinas en general, a los mellizos se le asignan poderes sobrenaturales y se conciben como depositarios de la dualidad humana, lo negativo y lo positivo, lo femenino y lo masculino, siendo así que se puedan complementar o destruir el uno al otro (Chevalier y Gheerbrant 1047I050).

La presencia de Marassá en el título de la novela de Lockward evoca el que se le da en Haití en la vida cotidiana para explicar relaciones interdependientes, ya sea de hermanos reales o no. ${ }^{8}$ Dado que son guardianes de bordes y umbrales, los cuales, a su vez, son metáforas de fronteras, evocan una modalidad de relación que se aparta del de 
"diferencias incompatibles" o de "conflicto fatal", de hostilidad y antagonismo que permea el debate sobre las relaciones entre ambas naciones. ${ }^{9}$ Al contrario, la metáfora de los Marassá, reforzada por la presencia de Moira y de las hermanas Laura y Mara, sugiere un modelo de relación de dos pueblos con diferencias y similitudes, pero que al final son mucho más poderosos cuando reconocen y aceptan la existencia del otro tal como es y aprenden a coexistir en armonía, complementándose y apoyándose el uno al otro. ${ }^{\text {IO }}$ En este contexto, Moira podría ser no sólo la Moerae o tres parcas, sino también la "dossa", o tercera hermana venida del exterior que teje la historia de las dos hermanas y/o de los dos pueblos. Quizás, si se extrapola la imaginación un poco más, como Moira llega a Santo Domingo y a Haití desde Nueva York, se podría interpretar como representación de una diáspora dominicana que intenta construir una narrativa viable de ambas naciones. Como bien señala Joan Dayan en la tradición vudú, "una persona o cosa puede ser dos o más cosas simultáneamente. Una palabra puede ser doble, tener dos significados, ser ambigua. En esta amplificación y multiplicación del significado de una palabra ... algo puede ser esto, pero también aquello" (33). ${ }^{\mathrm{II}}$

La novela de Lockward no es la primera en utilizar la figura de hermanos o gemelos para evocar dinámicas socioculturales o políticas entre los dos países. En la literatura haitiana, la imagen de los mellizos aparece en The Farming of Bones (1998), de Edwidge Danticat, quien la emplea para representar una dicotomía domínico-haitiana antagónica. Aquí, el personaje de Valencia tiene dos hijos mellizos, un niño, cuya piel blanca pretende evocar el linaje español de su madre, y una niña, cuya piel oscura podría hacerla parecer haitiana $(9$, I2, I9, 20 y 35). El hecho de que la pequeña Rosalinda, al nacer, sea de la mitad del tamaño de su hermano y salga con el cordón umbilical alrededor del cuello, "como si su hermano hubiera querido ahorcarla en el vientre", resalta el aspecto de rivalidad y antagonismo reproducido por las narrativas que pretenden definir las relaciones domínico-haitianas como intrínsecamente hostiles $\mathrm{y}$ conflictivas.

Por otro lado, en The Marassa Concept in Lilas Desquiron's Reflections of Loco Miwa, Florence Bellande-Robertson interpreta el concepto de los Marassá como figura literaria empleada por la escritora haitiana Lila Desquiron para ilustrar la tesis de una "bipolaridad" de la cultura haitiana, es decir, dos fuerzas y cosmogonías opuestas que, a su entender, coexisten en Haití, a veces de manera destructiva (xi). Esta bipolaridad se encontraría manifiesta en Les chemins de Loco-miroir, que es el título de la novela de Desquiron, por Violaine y Cocotte, dos personajes centrales que, aunque no son hermanas, representarían la dualidad existente en Haití por 
ser cada una de una raza y de una clase social opuestas. Asimismo, para Bellande-Robertson, la figura de Marassá también representaría la hibridez (europea y africana) racial y cultural de Haití, encarnada en el personaje de la mulata Violaine, hibridez que Bellande-Robertson concibe como la unificación de las dos fuentes (o tres, si se incluyen los vestigios taínos) de origen racial, cultural e histórico de Haití.

A diferencia de estos antecedentes en las novelas de Danticat y Desquiron, el concepto de hermandad evocado en Marassá y la Nada se distancia del antagonismo racial y nacional y reproduce la imagen de fraternidad inseparable descrita por Deren. De hecho, lejos de insistir en el conflicto, los agravios y las heridas, la imagen de Marassá contiene un importante aspecto de protección y curación. Tanto en el panteón sincrético del vudú dominicano como en el haitiano, Marassá corresponde a la figura de los santos Cosme y Damián, hermanos mellizos sirios del siglo III, primeros mártires del cristianismo y médicos que se granjearon una gran popularidad por ejercer su profesión de manera gratuita. En 526 530 el papa Félix los nombró santos patronos de los médicos. Cuenta la leyenda recogida por Jacobus de Voragine (1969) que en el siglo XIII, los santos salvaron la vida de un presbítero de París en cuya iglesia se les veneraba. Estando el presbítero enfermo de una pierna con gangrena, soñó una noche que Cosme y Damián le realizaban una operación mediante la cual le cortaban la pierna y la sustituían con la de un etíope muerto la noche anterior $(575-578) .{ }^{12}$

Según el historiador Carlos Esteban Deive, dicho milagro fue luego representado por varios pintores de los siglos XVI y XVII, incluyendo el artista Jaime Huguet, cuya pintura se conserva en la iglesia de Santa María de Tarrasa, en Barcelona, y Fernando del Rincón cuya obra se preserva en el Museo del Prado (239). En República Dominicana, la correspondencia entre los santos médicos y los Marassá aparece en grabados que presentan a los santos lado a lado, de pie, vestidos con una túnica verde y manto rojo, con una palma de mártires y una caja con inyecciones en las manos, mientras que en las representaciones haitianas, los santos aparecen vestidos de dorado, con capas rojas y verdes respectivamente, y en vez de la palma y la caja, sostienen un copón y un libro (239). Es preciso notar, sin embargo, que según las descripciones de Marilyn Houlberg, estas distinciones no existen, ya que los santos en Haití también sostienen palmas en sus manos, las cuales se interpretan como hojas curativas (I8). Houlberg también menciona otros santos católicos con los cuales se han asociado los Marassá en Haití, como Santa Clara y San Nicolás, padres de los mellizos, y que Houlberg identifica como paralelos a las deidades Mawu-Lisa de la tradición fon de África Occidental. Mawu, un ser 
femenino, se iguala a la luna, mientras que Lisa, el varón, se iguala al sol. En el vudú haitiano, Santa Clara se asocia a la luna porque sostiene una hostia en forma de luna, mientras que San Nicolas se asocia con el sol y su ceremonia se celebra el 6 de diciembre (I8). Finalmente, otra cromolitografía católica asociada con los mellizos retrata a tres niñas en las nubes, las hermanas Fe, Esperanza y Caridad, mártires preadolescentes que se dice vivieron en el siglo II. Como fueron decapitadas, solo se muestran sus cabezas y sus hombros flotando en el cielo. La cromolitografía cubierta con plástico transparente forma el centro de la bandera del vudú dedicada a las tres mellizas.

Menciono esta correspondencia entre los Marassá y los santos cristianos para enfatizar tanto el aspecto de sincretismo como el de curación, así como la asociación con las hermanas Fe, Caridad y Esperanza, que podrían corresponder, en su "trillizidad," a las Parcas, a Moira, Laura y Mara, o al trío de tejedoras del tiempo constituido por Moira, Carmen y Cassandra, mencionado al principio de este artículo. Contrario a las nociones predominantes de antagonismo y conflicto, estas figuras míticas, protectoras y curadoras realzan dinámicas de armonía, solidaridad y fraternidad.

En Marassá y la Nada, el aspecto de sincretismo religioso y de curación se ve claramente bajo el lente microscópico cuando la narradora Moira, avatar de las parcas inventoras del alfabeto, hilvana referencias cristianas y del vudú a través de anagramas o deconstrucciones silábicas de palabras. La primera ocasión en la que se entrega a este juego es con los nombres de su prima Mara y el propio, Moira: "mara, arma, rama, amar, ram, mar, ama; moira, rimo, rima, miro, mira, morí, mora, oír, ira, amo... Mara y yo nos entendimos como dos crías que habiendo abandonado la madriguera se reconocen en la madurez por el olfato y las manías, los anagramas y los bizcochos" (5I). Estos nombres y objetos surgen como imágenes en un espejo, invertidos y multiplicados en posibilidades simbólicas infinitas, donde lo más importante, al final, es reconocer los lazos de parentesco entre una de las hermanas y la narradora Moira. Más adelante, Moira repite este anagrama de deconstrucción: "En Haití, los gemelos se llaman Marassá. RAM, mar, Mara, arma, amar, amarás...” (63). La narradora explica quiénes son los Marassá y hace un juego de inversiones de letras con palabras sencillas pero significativas como "mar" "RAM", "arma", "amar", hasta llegar a una articulación muy precisa de esta inversión en los términos "marassá" y "amarás". Aquí, como si tejiera el vínculo entre el este y el oeste de la isla, entre el pasado, el presente y el futuro, Moira traslada la última "a" de "marassá" al inicio de "mara", le deja una de las dos eses (quizás las eses que inician los nombres de Saint- 
Domingue/Santo Domingo), y reconstituye "amarás". Es entonces que el o la lector/a perspicaz puede hacer la conexión de "amarás" con un epígrafe que aparece al inicio de la novela, consistente en puntos suspensivos que sustituyen "amarás", seguidos de la frase "...como a ti mismo", completando el precepto cristiano "Amarás a tu prójimo como a ti mismo." La letra A, la primera del alfabeto inventado por las regidoras del destino y del hilo de la vida, abre así un sistema lingüístico de conexiones silábicas entre una lengua y la otra, entre una cosmogonía y la otra, entre una cultura y la otra, entre un pueblo y otro. Esto nos permite observar ahora el significado simbólico de Marassá y la nada bajo el lente telescópico, el de las abstracciones cósmicas, y ver que la primera letra del alfabeto actúa de Poteau-Mitan, aquel tronco que marca el espacio de la encrucijada en el que se intersectan dos mundos físicos y materiales y dos mundos metafísicos, el del vudú y el del cristianismo, una cosmogonía regida por unos gemelos, los Marassá o santos Cosme y Damián, y otra regida por una madre, la Virgen de la Altagracia, amada en ambos lados de la isla. En fin, con la deconstrucción silábica y el reflejo entre Marassá y Amarás se ofrece una llave simbólica de apertura entre ambas naciones, se deshacen los nudos que los atan a cada uno de espaldas al otro y se propone un estado ideal de coexistencia en paz y armonía.

\section{Borough of Manhattan Community College, City University of New York}

\section{NOTAS}

I Este artículo se inspira también de Mito y cultura en la era de Trujillo, de Andrés L. Mateo, estudio fundamental del uso del mito en la construcción de una narrativa fundacional de la nación en el contexto de la República Dominicana.

2 Esta imagen se construye con el empleo de vocabulario con términos como "consumir", "absorber", "engullir", "tragar", etc. en referencias a la presencia haitiana en el país. Para algunos ejemplos, véase Joaquín Balaguer, La isla al revés (63; 156), así como una carta del 9 de octubre de 1945 en la que justifica la masacre de 1937 afirmando que "La República Dominicana estaba...condenada a desaparecer absorbida por Haití, raza más prolífica y homogénea que la nuestra. Varios lustros más y el país se hubiera haitianizado irremediablemente. Danna G. Munro, de la comisión de asuntos interamericanos, pinta esa situación tremenda en un documento que debería conocer toda la América: 'He ahí una ola de color que avanza y que se tragará 
sin remedio a la República Dominicana" (Cuello 504). Mi agradecimiento a Manuel Antonio Victoriano Martínez por señalarme este documento.

3 Dichos reportajes, que aparecieron recopilados bajo el título de Un Haití dominicano, fueron inicialmente recogidos en Un Haití dominicano. Tatuajes fantasmas y narrativas bilaterales. 1994-2006. Se trata de entrevistas, ensayos y reportajes realizados por la autora desde su primer viaje, y cuyo primer capítulo, Port-au-Prince: Mon Amour, fue publicado en 1994 en el periódico dominicano Listín Diario.

4 Para más detalles sobre el envío de esclavos libertos durante ese período, véase Dennis Hidalgo.

5 Según Torres-Saillant, este final expresaría un deseo que no corresponde a los hechos históricos ya que los taínos nunca lograron avanzar su lucha por la justicia y la igualdad (Intellectual 210). Sin embargo, comparado con su contraparte dominicana, es indudable que el autor haitiano propone un modelo mucho más satisfactorio que lo que se ofrece en el canon dominicano. Para un estudio reciente de distintas versiones de Anacaona en las letras de ambos países, ver Fumagalli.

6 El concepto glissantiano de creolización surge del término "creole" para referirse a las lenguas que nacieron del contacto de elementos lingüísticos provenientes de amos europeos y esclavos africanos en las colonias del Caribe. Aunque dichas lenguas surgen de un contexto violento y traumático, estructurado por relaciones de poder, Glissant insiste en explorar esta situación lingüística como una oportunidad para superar conceptos occidentales de identidad monolítica basadas en filiación, esencia y universalismo, y proponer conceptos que resultan de las conexiones (choques, armonías, deformaciones, retiros, repudios y atracciones) entre las culturas. En vez de identidades fijas y estáticas, la creolización propone resultantes en constante proceso, en constante cambio, constantemente impredecibles e inmensurables (Glissant II $^{-25}$ ).

7 Agradezco infinitamente a la Dra. Ivette Romero, especialista en estudios del Caribe, por introducirme al trabajo de Maya Deren y Marilyn Houlberg. Ver también el trabajo teórico de Vèvè Clark, el cual sitúa el concepto de Marassá dentro de una tradición más amplia de literatura afro-caribeña. Según Clark, el signo de Marassá también puede interpretarse como uno que "deconstruye" el sistema binario que aparenta ofrecer la figura gemela $\left(43^{-} 44\right)$.

8 En una entrevista sobre el origen del título de la novela, Lockward me explicó que oyó el término de Marassá por primera vez cuando estaba en Haití a finales de la década de los noventa y oía a la gente referirse a Aristide y René Préval como "marassá", es decir, rivales que se necesitan pero que no dejan de disputarse. Al momento de imaginar un título para su novela, Lockward 
deseaba sobre todo que la imagen del "espejo" estuviera incluida, pues el título original había sido El espejo de Mara (Entrevista personal, junio 2014).

9 El argumento de las "diferencias irreconciliables" forma parte de la tesis antihaitiana propulsada por Manuel Arturo Peña Batlle, Joaquín Balaguer y, más recientemente, Manuel Núñez. La misma ha sido profusamente desmantelada en ensayos de historiadores y críticos dominicanos como Franklyn Franco Pichardo, Odalís Pérez y, en la diáspora dominicana, Silvio Torres-Saillant, Néstor Rodríguez y Ramón Antonio Victoriano-Martínez, entre otros. En cuanto al debate sobre el modelo de "conflicto fatal", este fue provocado por la periodista norteamericana Michelle Wucker, cuya obra titulada Why the Cocks Fight? Dominicans, Haitians and the Struggle for Hispaniola fue objeto de crítica por parte de Samuel Martínez, quien objetó el carácter reduccionista de este modelo. En mi opinión, la metáfora de gallos de pelea es un recurso poco afortunado (por no decir ofensivo) para representar a ambos pueblos, pues evoca la conocida mirada imperialista que despoja a sus sujetos de su humanidad y los reduce a simples animales en estado de pelea territorial. De hecho, este modelo obvia la muy cierta observación de Franklyn Franco Pichardo, según el cual la llamada historia de "conflicto" entre los dos países es una historia de sus élites respectivas, no de sus pueblos, pues la de estos queda aún por escribirse (98). En este sentido, véase también la certera crítica del trabajo de Wucker en Manuel Antonio Victoriano-Martínez. Por otra parte, el crítico Eugenio Matibag ya ha analizado textos literarios que replantean las relaciones domínico-haitianas, como Over, de Ramón Marrero Aristy, Compadre Mon, de Manuel del Cabral (1940), algunos poemas del movimiento de la Poesía Sorprendida (1940-1943), "Cantos de la Frontera" (1963) de Manuel Rueda, y Pirámide 179 y tres cuentos de la colección Máscaras de la seducción (1983) de José Alcántara Almánzar. Según Matibag, estos textos propondrían "una renovación del contrapunto domínico-haitiano, ya que reconocen las similitudes y fortalecen los vínculos que unen a los dos pueblos a través de una historia de opresión compartida" (I67; mi traducción). Más recientemente, María Cristina Fumagalli ha elogiado la obra de Wucker pero señala que este "conflicto" tiene solución y que no todos los dominicanos son hostiles a Haití.

Io La crítica Lucía M. Suárez también se refiere brevemente a los Marassá como metáfora para interpretar la relación de ambos países, pero deja sin desarrollar la idea. Para un análisis de este estudio, ver Ramón Antonio Victoriano-Martínez.

II Para una reciente introducción al aspecto de creolización en el vudú, y específicamente el vudú en Haití, ver también el estudio de Margarite Fernández Olmos y Lisa Paravisini-Gebert, Creole Religions of the Caribbean: An Introduction from Vodou and Santería to Obeah and Espiritismo. 
I2 Ver también un estudio reciente de Cosme y Damián en Jacalyn Duffin (2013).

OBRAS CITADAS

A LE XA N RE, G uy. Pour Haïti. Pour la République Dominicaine: Interventions, positions et propositions pour une gestion responsable des relations bilatérales. Pétion-Ville: $\mathrm{C}_{3}$ Editions, 2013 .

Alvarez, Julia. A Wedding in Haiti. New York: Penguin, $201 \mathrm{I}$.

B A A G U R, Jo Aquín. La isla al revés: Haití y el destino dominicano. Santo Domingo:

Fundación José Antonio Caro, 1983.

BARTHES, Ro LAn D. S/Z. Paris: Seuil, 1970.

-. Le plaisir du texte. Paris: Seuil, r973.

-. L'aventure sémiologique. Paris, Seuil, 1985 .

Bellande-Ro Bert SOn, Florence. The Marassa Concept in Lilas Desquiron's

Reflections of Loko Miwa. Dubuque: Kendall/Hunt Publishing Company, I999.

CLARK, VÈ VÈ A. "Developing Diaspora Literacy and Marassa Conscioussness".

Comparative American Identities. Ed. Hortense Spillers. New York: Routlege, I99I. 40-6I.

Chevalier Jean y alain gheerbrant. A Dictionary of Symbols. London: Penguin, I994.

Cuello, José isRae L. Documentos del conflicto domínico-haitiano de 1937. Santo Domingo: Editora Taller, 1985 .

DAntiCat, EDWIDGE. The Farming of Bones. New York: Soho Press, 1998.

D AYA N, J O A N. Haiti, History and the Gods, Berkeley/Los Angeles: U of California P, I998.

DEREn, MAYA. Divine Horsemen: The Living Gods of Haiti. New York: Thames and Hudson, 1953 .

Deive, Carlos esteban. Vodú y magia en Santo Domingo. Santo Domingo: Fundación Cultural Dominicana, 1996.

DELGAD O PANTALEÓN, MÉlidA. "Historia del comegente con sus conclusiones". La cítara campestre cibaeña: la criolla, poesía, ensayos, cuentos cibaeños. Santo Domingo: Editorial Amigo del Hogar, 1989. 295-336.

D O N G E R, W E N DY. The Implied Spider: Politics and Theology in Myth. New York: Columbia UP, I999.

D uf f in, JA CA ly n. Medical Saints: Cosmas and Damian in a Postmodern World. New York: Oxford UP, 2013.

fernández olmos, margarite, y lisa paravisini-gebert. Creole Religions of the Caribbean: An Introduction from Vodou and Santería to Obeah and Espiritismo. New York: New York UP, 2003.

FRAn Co P ICHARDo, FRAnKLyn. Du racisme et de l'anti-haïtianisme. Pétion-Ville: C3 Editions, 20I3. 
fumagalli, maría cristina. On the Edge: Writing the Border between Haiti and the Dominican Republic. Liverpool: Liverpool UP, 2015.

GL ISS A N T, ED OUARD. Introduction à une poétique du divers. Paris: Gallimard, 1996. GONZÁLEZ, RAYMUNDO. "El Comegente, una rebelión campesina al final del periodo colonial". Homenaje a Emilio Cordero Michel. Santo Domingo: Academia Dominicana de la Historia, 2004. 175-224.

graves, ro bert. "The Fates." The Greek Myths, New York: Penguin, 1960.

HidALG O, DENis. "From North America to Hispaniola: First Free Black Emigration and Settlements in Hispaniola". Diss. Central Michigan University, 200 I.

h o Ulberg, MAR ILyn. "Magique Marasa: The Ritual Cosmos of the Twins and Other Sacred Children". Fragments of Bone: Neo-African Religions in a New World. Urbana: U of Illinois P, 2005. I3-31.

JÁuREgui, CARlos. "El 'Negro Comegente': Terror, colonialismo y etno-política”. Afro-Hispanic Review 28:I (2009): 45-79.

JoHnson, SARAH E. The Fear of French Negroes: Transcolonial Collaboration in the Revolutionary Americas. Berkeley y Los Angeles: U of California P, 2012.

KRISTEVA, J ULIA. Recherches pour une séminalyse. Paris: Seuil, 1969.

-. Le Texte du roman. La Haye-Paris: Mouton, I970.

L o C KWA R, A Lanna. Marassá y la Nada. Santo Domingo: Santuario, 2013.

-. Un Haití dominicano. Santo Domingo: Santuario, 2014.

LORA H., QUISQUEYA. "La construcción de Haití en el imaginario dominicano del siglo XIX”. República Dominicana y Haití: Derecho a vivir. Santo Domingo:

Fundación Juan Bosch, 20I4. I71-204.

LISTER, ELISSA L. Le conflit haïtiano-dominicain dans la littérature caribéenne. Pétion-Ville: $\mathrm{C}_{3}$ Editions, 2013.

м а ті в A, e u g E I o. Haitian-Dominican Counterpoint: Nation, Race, and State on Hispaniola. New York: Palgrave-MacMillan, 2003.

MA R Tí N EZ, SAM UE L. "Not a Cockfight: Rethinking Haitian-Dominican Relations". Latin American Perspectives: Popular Participation against Neoliberalism 30.3 (2003): 80-IOI.

MATE 0, AN DRÉS L. Mito y cultura en la era de Trujillo. Santo Domingo: La Trinitaria/Instituto del Libro, I993.

métellus, jean. Anacaona: Théâtre. Paris: Hatier, 1986.

mét RAUX, ALFRED. Voodoo in Haiti. New York: Schocken, I959.

Miller, NAnCY K. "Arachnologies: The Woman, the Text, and the Critic". The Poetics of Gender. New York: Columbia UP, 1986. 270-95.

PÉREZ, ODALís. La ideología rota: El derrumbe del pensamiento pseudo-nacionalista dominicano. Santo Domingo: Centro de Información Afro-americano, 2002.

RODRÍGUEZ, NÉS TOR. La isla y su envés: representaciones de lo nacional en el ensayo dominicano contemporáneo. San Juan: Instituto de Cultura Puertorriqueña, 2003. 
Rueda, manue L. Las metamorfosis de Makandal. Santo Domingo: Banco Central de la República Dominicana, I998.

Som MER, D ORIs. One Master for Another: Populism as Patriarchal Rhetoric in Dominican Novels. Lanham: UP of America, I983.

SuÁREZ, LuCíA M. The Tears of Hispaniola: Haitian and Dominican Diaspora Memory. Gainsville: UP of Florida, 2006.

T O R R S S-S A L LA N T, Silvio. An Intellectual History of the Caribbean. New York: Palgrave Macmillan, 2006.

-. "Introduction to Dominican Blackness". Dominican Studies Working Papers Series, No. 1, New York: CUNY Dominican Studies Institute, I999.

ubaldo gómez, manuel. Resumen de la historia de Santo Domingo. La Vega: Imprenta El Progreso, I92O.

u Reña, Salo mé. Anacaona. Santo Domingo: Publicaciones América, I970. VICT OR I AN O-MARTínez, RA Món ANTon Io. Rayanos y Dominicanyorks: La dominicanidad del siglo XXI. Pittsburg: Universidad de Pittsburg/Instituto Internacional de Literatura Latinoamericana, 2OI4. VorAG InE, J AC о B US DE. "Cosmas and Damian". The Golden Legend. New York, London, Toronto: Longmans, Green and Co., 1969. 575-578.

W U C KE R, M I C H E LE. Why the Cocks Fight? Dominicans, Haitians and the Struggle for Hispaniola. New York: Hill and Wang, 2000. 